REVIEW

\title{
Treatment of scabies: newer perspectives
}

\author{
K Karthikeyan
}

Postgrad Med J 2005;81:7-11. doi: 10.1136/pgmj.2003.018390

Scabies is a common dermatological problem managed by general physicians, family physicians, and dermatologists. Scabies manifests itself in various forms in different individuals. The treatment of scabies has undergone developments with the evolution of new treatment strategies and antiectoparasitic drugs. The advent of drugs such as permethrin and ivermectin has revolutionised treatment. Management of scabies not only includes prescribing the drugs but also educating patients properly about the method of application of the drug. Treatment failures may result for various reasons and must be managed appropriately.

Correspondence to:

Dr Kaliaperumal

Karthikeyan, Pondicherry, India; karthikderm@

yahoo.co.in

Submitted

29 December 2003

Accepted 12 April 2004
S cabies has presumably afflicted humanity since antiquity. ${ }^{1}$ It is caused by the mite Sarcoptes scabiei var hominis, an obligate human parasite measuring about 300-400 microns. ${ }^{2}$ The mite burrows a tunnel in the stratum corneum and completes its life cycle there. ${ }^{3}$ Treatment of "the itch" has undergone various changes from the days of Celsus when sulphur mixed with liquid pitch was used in treatment. Many drugs, particularly insecticides, were used to treat scabies in the 20th century. However, most of them had an innate toxicity. More recently, reports of resistance to various existing drugs, the severe course of the disease, and adverse drug reactions have prompted the development of new treatment strategies and antiectoparasitic drugs for optimal management. ${ }^{4}$

\section{EPIDEMIOLOGY}

All races, ages, and social levels are susceptible to scabies and the disease has a worldwide distribution. ${ }^{5}$ In 1941, Freidman noted "the Acarus scabiei [Sarcoptes scabiei] is notorious for its lack of respect for person, age, sex or race. Whether it is in the epidermis of an emperor or a slave, a centenarian or a nursling, it makes itself perfectly at home with undiscriminating impudence and equal obnoxiousness". ${ }^{5}$ There are about 300 million cases of scabies in the world each year. ${ }^{6}$ The burden of the disease is highest in developing countries where the disease is endemic, and in certain Indian villages, the prevalence is about $100 \% .^{7}$ In the developed world, scabies occurs as an epidemic in hospitals, nursing homes, and long term care facilities. ${ }^{8}$

\section{MODE OF TRANSMISSION}

Scabies is usually contracted from another person by direct skin-to-skin contact. ${ }^{9}$ It can also be transmitted by sexual contact.

\section{CLINICAL MANIFESTATIONS}

The incubation period of scabies is three weeks. In cases of reinfestation, symptoms develop in 1-3 days. ${ }^{3}$ Patients with scabies complain of itching, which is most severe at night. The most characteristic lesion is the burrow, the linear tunnel in which the mite lives. Burrows occur as wavy, dirty appearing line in the interdigital web spaces (see fig 1). ${ }^{10}$ Other skin manifestations include papules, blisters, nodules, and eczematous changes. The skin lesions commonly involve web spaces, flexor surface of wrists, axillae, waist, feet, and ankles. Different types of scabies have been described based on the clinical features such as nodular scabies, bullous scabies, and crusted scabies. ${ }^{3} 811$

The papular pustular, pruritic eruption or rash of scabies is caused by burrowing and the release of toxic or antigenic secretions of the mite. Itching takes approximately four to six weeks to develop and is thought to be due to sensitisation.

Scabies in infants differs from adults in many ways. Facial and palmoplantar involvement is unique to infantile scabies..$^{12}$

Atypical lesions such as vesicles, pustules, and nodules are seen in children. ${ }^{3}$

Crusted or Norwegian scabies occurs commonly in the immunocompromised (AIDS patients, organ transplant recipients) and in those who are mentally or physically handicapped (for example, patients with leprosy or paraplegia). It is characterised by psoriasiform or warty lesions accompanied by nail hyperkeratosis and patients complain of minimal itching. ${ }^{5}$ The average number of mites in these cases is two million; it is highly contagious and may be the source of epidemics. ${ }^{12}$

\section{DIAGNOSIS}

Scabies is one of the easiest and yet most difficult diagnoses in dermatology. ${ }^{14}$ Epidemiological history, the occurrence of itching, distribution of the lesions, and pruritus form the basis of the diagnosis." Definitive diagnosis is made by microscopic identification of mites, eggs, or mite faeces (scybala) from skin scrapings or epiluminescence microscopy. The scabies mite can be picked from the end of the burrow but this requires skill and practice. Skin scrapings from the burrow or the papule are useful in diagnosis of scabies. At first, a drop of mineral oil is placed on a sterile scalpel blade and five to six suspicious lesions are scraped. The scrapings and oil are placed on a glass slide and covered with a cover slip for examination. The presence of any stage of the mite is diagnostic. Though this procedure is simple, a skilled technician or dermatologist is required to obtain good results. 


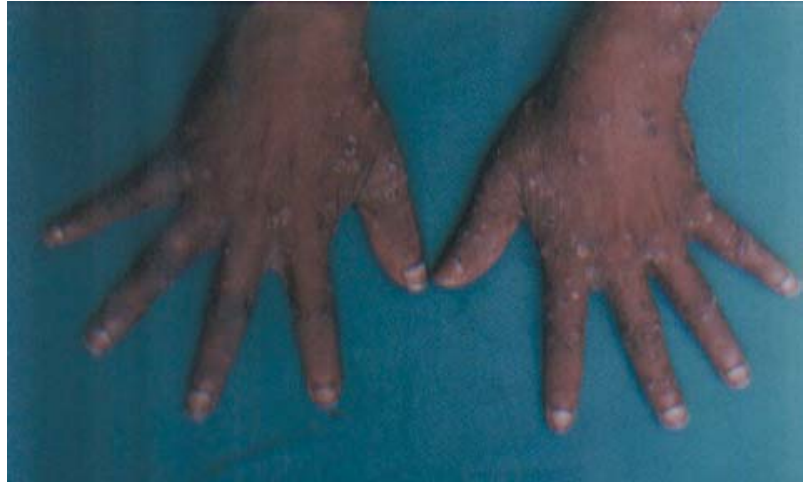

Figure 1 Finger web spaces with typical scabies lesions (reproduced with patient's permission).

In many countries where scabies is endemic these facilities do not exist and hence diagnosis is made based on the history and clinical features. Further, if there is a clinical suspicion the diagnosis is scabies until proven otherwise. ${ }^{15}$

\section{TREATMENT}

The treatment of scabies is as important as making a correct diagnosis. The mainstay of treatment is topical scabicidal agents. Certain principles have to be followed to treat patients successfully and are summarised in box 1 .

Patients should be properly instructed about the method of using the scabicide; this information can also be given as a pamphlet. A typical instruction sheet is shown in box 2, and it can be modified to suit the drug.

Various treatment modalities have been used since time immemorial but the search for an ideal scabicide is ongoing. An ideal scabicide should be effective against adult and egg, easily applicable, non-sensitising, non-irritating, non-toxic, and economical ${ }^{2}$; it should also be applicable in all ages. As yet, no drug can be considered an ideal scabicide.

\section{Drugs}

Scabicidal drugs can be broadly divided into topical agents and oral agents. The various topical agents that are used in the treatment of scabies are summarised in box 3 (drugs that are not used now are not listed).

The topical and oral agents that are used in both in developed and developing countries are discussed below.

\section{Box 1: Principles of treatment of scabies}

- Establish your diagnosis.

- Choose an appropriate medication.

- Treat the whole body from neck to toes in adults and head and face in babies.

- Treat all the contacts.

- Give a detail verbal and written prescription.

- Treat secondary infection if present.

- Avoid over treatment.

- Have a follow up at one and four weeks after treatment.

- Launder clothing and bedding after completing treatment.

\section{Box 2: Instructions to patients}

Instructions for the treatment of scabies

Scabies is caused by itch mite and it can be easily cured if the following instructions are followed carefully:

1. Start with a warm bath and dry thoroughly afterwards.

2. The medication provided should be rubbed into the skin. All parts of the body from chin downwards, whether involved or uninvolved should be treated.

3. Treatment is best done at night before going to bed.

4. Avoid touching your mouth or eyes with your hands.

5. Change your underclothing and sheets the next day and launder them.

6. You may itch for few days but do not repeat the treatment.

7. Everyone in the house should be treated at the same time.

8. Report to your doctor after one week.

Modified from Alexander's Arthropods and Skin ${ }^{2}$

\section{Topical agents}

\section{Sulphur}

Sulphur is the oldest antiscabietic in use. Celsus used sulphur mixed with liquid pitch for management of scabies as early as $25 \mathrm{AD}^{1}{ }^{19}$ Sulphur is used as an ointment $(2 \%-10 \%)$ and usually $6 \%$ ointment is preferred. The technique is very simple: after a preliminary bath, the sulphur ointment is applied and thoroughly rubbed into the skin over the whole body for two or three consecutive nights. ${ }^{16}$ Patients should apply the ointment personally, as it ensures that their hands will be well impregnated. Ointments are more useful than any other preparation. ${ }^{217}$

Topical sulphur ointment is messy, malodourous, stains clothing, and in a hot and humid climate may lead to irritant dermatitis. ${ }^{9}$ It has the advantage of being cheap and may be the only choice in areas of the world where the need for mass therapy or economy dictates the choice of scabicide. ${ }^{7}$

Sulphur should be used only in situations where adults cannot tolerate lindane, permethrin, or ivermectin as it is inferior to all these agents. ${ }^{4}$ Sulphur is recommended as a safe alternative for the treatment of scabies in infants, children, and pregnant women. ${ }^{3}$

Box 3: Antiscabietic drugs

\section{Topical agents}

- Permethrin 5\% cream.

- Lindane (gamma benzene hexachloride) $1 \%$ lotion or cream.

- Benzyl benzoate $10 \%$ and $25 \%$ lotion or emulsion.

- Malathion 0.5\% lotion.

- Monosulfiram 25\% lotion.

- Crotamiton $10 \%$ cream.

- Precipitated sulphur 2\%-10\% ointment.

- Esdepallethrine 0.63\% aerosol.

- Ivermectin $0.8 \%$ lotion.

Oral drug

- Ivermectin. 


\section{Benzyl benzoate}

Benzyl benzoate, an ester of benzoic acid and benzyl alcohol is obtained from balsam of Peru and Tolu. Benzyl benzoate is neurotoxic to the mites. It is used as a $25 \%$ emulsion and the contact period is 24 hours. Benzyl benzoate should be applied below the neck three times within 24 hours without an intervening bath. ${ }^{4} 9$ In young adults or children, the dosage can be reduced to $12.5 \%$. Benzyl benzoate is very effective when used correctly. If not properly applied, it may lead to treatment failure. Moreover, it can also cause irritant dermatitis on the face and scrotum. Repeated usage may lead to allergic dermatitis. It is forbidden in pregnant and lactating women, infants, and young children less than 2 years of age. ${ }^{4}$ Because of the side effects and the availability of less toxic agents, this scabicide had fallen into disrepute. ${ }^{4}$ However, recent studies have found it to be effective in the management of permethrin resistant crusted scabies ${ }^{18}$ and in combination with ivermectin in patients with relapses after a single treatment with ivermectin. ${ }^{19}$ In developing countries where the resources are limited, it is used in the management of scabies as a cheaper alternative.

\section{Crotamiton}

Crotamiton (crotonyl- $N$-ethyl-o-toluidine) is used as $10 \%$ cream or lotion. The success rate varies between $50 \%$ and $70 \%$. The best results have been obtained when applied twice daily for five consecutive days after bathing and changing clothes. ${ }^{20}{ }^{21}$ However, much stress has been put on its antipruritic properties but recent studies have not revealed any specific antipruritic effects. ${ }^{12}$ Some authors do not recommend crotamiton because of the lack of efficacy and toxicity data. $^{5}$

\section{Monosulfiram}

The chemical name of monosulfiram is tetraethyl thiuram monosulphide. Percival first used it to treat human scabies in 1942..$^{22}$ Monosulfiram emulsion is applied all over the body after a bath, ${ }^{9}$ and it should be rubbed in well once a day on two or three consecutive days. Monosulfiram is chemically related to antabuse and hence alcoholic beverages should be avoided during or soon after treatment. ${ }^{2}$ Soaps containing monosulfiram have been used in the past as a prophylactic measure in infected communities. ${ }^{9}$

\section{Malathion}

Malathion is an organophosphate insecticide that irreversibly blocks the enzyme acetylcholinesterase. Malathion is not recommended nowadays for treatment of human ectoparasitic infestations because of the potential for severe adverse affects. ${ }^{4}$

\section{Lindane}

Lindane, also known as gamma benzene hexachloride, is an insecticide. Wooldridge first used it to treat scabies in $1948 .^{23}$ It acts on the central nervous system (CNS) of insects and leads to increased excitability, convulsions, and death. Lindane is absorbed through all portals of entry including the lung mucosa, intestinal mucosa, and other mucous membranes and it is distributed to all body compartments with the highest concentration in lipid-rich tissue and the skin. It is metabolised and excreted in urine and faeces. ${ }^{4}$

A single six hour application is effective in treatment of scabies. Some authors recommend a repeat application after one week. ${ }^{92}$ Lindane $1 \%$ cream or lotion has been found to be very effective in the treatment. It is non-irritating and ease of application has made it a popular treatment. Its disadvantage is that it can cause CNS toxicity and rare cases of CNS toxicity, convulsions, and death have been reported. However, all these reports are in children or infants with overexposure or an altered skin barrier (which increases lindane absorption). ${ }^{9}$ Accidental ingestion can lead to lindane poisoning. The clinical signs of CNS toxicity after lindane poisoning include headache, nausea, dizziness, vomiting, restlessness, tremors, disorientation, weakness, twitching of eyelids, convulsions, respiratory failure, coma, and death. ${ }^{24} 25$ There is some evidence that lindane may affect the course of haematological abnormalities such as aplastic anaemia, thrombocytopenia, and pancytopenia. ${ }^{26}$ To reduce the incidence of failure and toxicity, the "do's and don'ts" relating to the use of lindane are described in table 1.

Despite the problems, the benefits outweigh the risk. ${ }^{9}$ It is a cheap and effective alternative to permethrin in many developing countries where scabies is widely prevalent. Rare reports of resistance to lindane exist. ${ }^{27}$

\section{Permethrin}

Permethrin is a synthetic pyrethoid and potent insecticide. ${ }^{4}$ Permethrin is very effective against mites with a low mammalian toxicity. Permethrin is absorbed cutaneously only in small amounts, rapidly metabolised by skin esterases, and excreted in urine. Permethrin 5\% dermal creams are applied overnight once a week for two weeks to the entire body, including the head in infants. The contact period is about eight hours. It is the latest and most effective treatment for scabies. ${ }^{4}{ }^{12}$ Permethrin can be safely used in young children. It has virtually no allergic side effects and cosmetically it is highly acceptable. Several studies have shown that permethrin has a higher clearance rate than lindane and crotamiton. ${ }^{28}$ The limiting factor in the use of permethrin is its cost as it is the most expensive of all the topical scabicides. ${ }^{4}$

The various topical antiscabietic agents and their side effects are summarised in table 2 .

\section{Oral antiscabietic agent}

\section{Ivermectin}

Ivermectin, the 22, 23 dihydro derivative of avermectin $B_{1}$ is similar to macrolides, but without any antimicrobial action. It acts via the suppression of conduction of nerve impulses in the nerve-muscle synapses of insects by stimulation of gamma amino butyric acid from presynaptic nerve endings and enhancement of binding to postsynaptic receptors. Scabies is treated with ivermectin $0.2 \mathrm{mg} / \mathrm{kg}$ in a single dose. ${ }^{29}{ }^{30}$ The clinical efficacy is good with good clearing of skin lesions and a marked decrease in pruritus. ${ }^{31}$ It is rapidly absorbed and excreted through the faeces. The toxic effect of ivermectin after a single dose for scabies appears to be insignificant. It is relatively safe with side effects such as headache, pruritus, pains in the joints and muscles, fever, maculopapular rash, and lymphadenopathy, which were observed in patients with filariasis. Whether these symptoms are directly related to drug action or secondary to destruction of the filariae remains unclear. ${ }^{4}$ Ivermectin is contraindicated in patients with an allergy to ivermectin and CNS disorders.

\begin{tabular}{ll}
$\begin{array}{l}\text { Table } 1 \text { "Do's and don'ts" } \\
\text { scabies }\end{array}$ & with the use of lindane in \\
\hline Do & Do not \\
\hline Apply lindane on a cool dry skin & $\begin{array}{l}\text { Do not use in sick children and } \\
\text { infants } \\
\text { Do not use in inflamed, excoriated, } \\
\text { or denuded skin } \\
\text { Do not use concentration less than } \\
1 \% \text { as it is ineffective }\end{array}$ \\
Apply only for 6 hours & $\begin{array}{l}\text { Do not prescribe in excess } \\
\text { Do not over treat the patient }\end{array}$ \\
$\begin{array}{ll}\text { Wash after } 6 \text { hours with soap and } \\
\text { Treat the family and contacts } \\
\text { Inform patients, parents, and } \\
\text { guardians about toxicity of lindane }\end{array}$ & \\
\hline
\end{tabular}




\begin{tabular}{|lll|}
\hline \multicolumn{2}{l}{ Table 2} & Topical \\
\hline Drugtiscabietics and their side effects \\
\hline Benzyl benzoate & Contact period & Side effects \\
Lindane & 24 hours & Contact dermatitis, stinging, and burning sensation \\
Monsulfiram & 6 hours & Neurotoxicity \\
Crotamiton & 48 hours & Irritation and antabuse-like reaction \\
Permethrin & 8 hours & Irritation \\
& & Contact dermatitis in preparations containing \\
& & formaldehyde \\
\hline
\end{tabular}

It is also not indicated during pregnancy, lactation, and in children less than 5 years of age. It is very effective, safe to use, cheap, and convenient. Ivermectin has been found to be useful in patients with a high mite burden such as crusted scabies in addition to keratolytics. ${ }^{29} 3032$ Ivermectin promises to be the drug of the future. Ivermectin lotion has also been used to treat scabies. ${ }^{33}$

\section{Other agents}

Allethrin I, widely used as an insect repellent, was effective when used as a spray in scabies. It is neither irritant nor sensitiser. Thiabendazole $5 \%$ cream has been tried in treatment of resistant scabies.

Although many drugs are used for treating scabies, recommendations for the management of scabies from the Centers for Disease Control in Atlanta include only lindane, permethrin, and ivermectin (see table 3). ${ }^{34}$

Among the various array of drugs available, the most suitable for the individual patient can be decided based on the factors ${ }^{2}$ shown in box 4 .

In general, the drug of choice for scabies is permethrin followed by lindane and benzyl benzoate. In most patients, permethrin $5 \%$ cream can be used safely except in pregnant and lactating women where it should not be used. Ivermectin is now emerging as an effective oral drug and can be used safely in adults. It is the agent of choice in Norwegian scabies and scabies epidemics in institutions. ${ }^{3}$ Lindane and benzyl benzoate still hold the sway in developing world where permethrin is beyond the reach of the poorest of the poor.

\section{MANAGEMENT OF SPECIAL FORMS OF SCABIES \\ Scabies in infants}

Sulphur $2 \%-10 \%$ in petrolatum can be used in infants. ${ }^{3}{ }^{12}$ Permethrin $5 \%$ cream is approved for use only in infants older than 2 months. ${ }^{4}$ Ivermectin and lindane are contraindicated in infants. ${ }^{\circ}$

\section{Scabies in children}

Permethrin 5\% cream is the most effective and safe modality of treatment in children. Benzyl benzoate can be diluted to $12.5 \%$ emulsion and used topically. Benzyl benzoate is a cheap alternative to permethrin in developing countries. ${ }^{9}$

Table 3 Centers for Disease Control recommendations for treatment of scabies

\begin{tabular}{ll}
\hline Drug & Instruction for use \\
\hline $\begin{array}{l}\text { Lindane 1\% } \\
\text { lotion }\end{array}$ & $\begin{array}{l}\text { Apply thinly to the whole body from head to neck down } \\
\text { and wash off completely after } 8 \text { hours }\end{array}$ \\
$\begin{array}{l}\text { Permethrin 5\% } \\
\text { cream }\end{array}$ & $\begin{array}{l}\text { apply to whole body from the neck down and wash off } \\
\text { after hours } \\
\text { Ivermectin }\end{array}$ \\
& $\begin{array}{l}\text { interval of } 2 \text { weeks; this is not a Food and Drug } \\
\text { Administration approved indication }\end{array}$ \\
\hline
\end{tabular}

Box 4: Factors deciding suitability of patient for various drugs

- Age of the patient.

- Pregnancy and lactation status if women.

- Efficacy of the drug.

- Extent of eczematisation.

- Potential toxicity of the agent.

- Cost effectiveness.

\section{Scabies in pregnant and lactating women}

In pregnant women and lactating women, 6\% sulphur precipitate is recommended. Ivermectin, permethrin, and lindane are contraindicated. ${ }^{4}$

\section{Nodular scabies}

Nodular scabies is a chronic form of scabies characterised by nodules on the covered parts of the body particularly on the male genitalia, groin, and axillary region. This type of scabies is treated with antiscabitics followed by intralesional steroids. ${ }^{12}$

\section{Crusted scabies}

Crusted scabies needs prolonged and persistent treatment. Oral ivermectin is effective but multiple doses plus topical agents may be required..$^{29} 3035$ The hyperkeratosis is treated with a keratolytic agent $(5 \%-10 \%$ salicylic acid in petrolatum). Nails are cut short and brushed with a scabicidal agent. A cure is obtained after a mean treatment of three weeks. ${ }^{3} 8$

\section{PROBLEMS ENCOUNTERED IN TREATMENT}

Certain problems are encountered in the treatment of scabies that are peculiar to scabies: persistent itching and resistance to the scabicidal.

\section{Persistent itching}

Itching usually persists for about one week after treatment but if it is present for longer then it should be evaluated. The cause of persistent itching and its treatment are shown in table 4.

Table 4 Causes and treatment of persistent itching in scabies

\begin{tabular}{ll}
\hline Causes & Treatment \\
\hline $\begin{array}{l}\text { Cutaneous irritation } \\
\text { Allergic contact dermatitis }\end{array}$ & $\begin{array}{l}\text { Topical steroids } \\
\text { Stop the scabicide: topical } \\
\text { steroids }\end{array}$ \\
$\begin{array}{l}\text { Treatment failure } \\
\text { Acarophobia (delusional the cause and treat it } \\
\text { parasitosis) }\end{array}$ & \begin{tabular}{l} 
Psychiatric management \\
\hline
\end{tabular} \\
\hline
\end{tabular}




\section{Causes of treatment failure}

The treatment of scabies can fail because of various reasons.

(1) Improper application

The drug should be applied from the neck downwards all over the body. The most common mistake is that the drug is applied only to the affected areas, which leads to a relapse of the disease. ${ }^{2}$

(2) Inadequate application

The drug dispensed should be used and it should not be diluted. When drugs like lindane are diluted, their efficacy is reduced. ${ }^{2}$

\section{(3) Reinfestation}

Reinfestation is a common problem and it occurs because of failure to treat contacts. It can be avoided if the instructions are clearly followed. ${ }^{2}{ }^{3}$

\section{(4) Resistance}

Resistance has been reported with drugs such as lindane, permethrin, and crotamiton. ${ }^{36}{ }^{37}$ Resistance to lindane has been reported in El Salvador, Peru, Panama, New Zealand, Egypt, and from 18 different locations in United States.' Resistance to permethrin is very rare and only isolated reports exist. In such areas, the combination of lindane and benzyl benzoate or permethrin can be used. Resistance should be considered only if all the other causes for treatment failure are ruled out.

Treatment of scabies not only includes a scabicidal but also symptomatic treatment in the form of antipruritics such as antihistaminics is essential to relieve itching. Moreover, if secondary bacterial infection is present it should be appropriately treated with antibiotics.

\section{CONCLUSION}

Sarcoptes scabiei is a highly parasitic blind insect, handicapped by its parasitism, as it cannot survive outside the human body. However, despite all its handicaps it survives and thrives probably because of failure on the part of human beings to understand its biology. Hence, in this review the stress has not only been on the recent advances in treatment but also on the practical aspects.

Scabies is a common dermatological problem that can be managed effectively if physicians possess an appropriate knowledge of the available drugs and instructs patients appropriately. It requires a willing physician and a cooperative patient to successfully treat this disease.

\section{REFERENCES}

1 Parish LC. History of scabies. In: Orkin M, Maibach HI, Parish LC, et al, eds Scabies and pediculosis. Philadelphia: Lippincott, 1977:1-6.

2 Alexander JOD. Arthropods and skin. Berlin: Springer-Verlag, 1984:50-5.

3 Chosidow O. Scabies and pediculosis. Lancet 2000;355:819-21.
4 Roos TC, Alam M, Roos S, et al. Pharmacotherapy of ectoparasitic infections. Drugs $2001 ; 61: 1067-88$.

5 Meinking TL. Infestations. Current Problems in Dermatology 1999;11:80-103.

6 Orkin M. Scabies: what is new? Curr Probl Dermatol 1995;22:105-111.

7 Behl PN, Taplin D. Eradication of scabies with a single treatment schedule [letter and response]. J Am Acad Dermatol 1985;12(1 pt 1):117-18.

8 Wendel K, Rompalo A. Scabies and pediculosis pubis: an update of treatment regimens and general review. Clin Inf Dis 2002;35(suppl 2):S146-5.

9 Taplin D, Meinking T. Infestations. In: Schachner LA, Hansen RC, eds. Pediatric dermatology. Vol 2. New York: Churchill Livingstone, 1988:1465-516.

10 Epstein E, Orkin M. Scabies: clinical aspects. In: Orkin M, Maibach HI Parish LC, et al, eds. Scabies and pediculosis. Philadelphia: Lippincott, 1977:17-22.

11 Orkin M. Special forms of scabies. In: Orkin M, Maibach HI, Parish LC, et al, eds. Scabies and pediculosis. Philadelphia: Lippincott, 1977:23-30.

12 Hogan DJ, Schachner L, Tanglertsampam C. Diagnosis and treatment of childhood scabies. Pediatr Clin North Am 1990;38:941-56.

13 Hurwitz S. Scabies in infants and children. In: Orkin M, Maibach HI, Parish LC, et al, eds. Scabies and pediculosis. Philadelphia: Lippincott, 1977:31-9.

14 Hurwitz S. Scabies in babies. Am J Dis Child 1973;126:226-8.

15 Parish LC, Witkowski JA. The saga of ectoparasitoses: scabies and pediculosis. Int J Dermatol 1999;38:432-3.

16 Lin A, Reamer R, Carter D. Sulfur revisited. J Acad Dermatol 1988; 18:553-8.

17 Percival CH. Organized treatment of scabies. $\mathrm{Br} J$ Dermatol $1941 ; 53: 346-350$

18 Anderson BM, Haughen $\mathrm{H}$, Rasch M, et al. Outbreak of scabies in Norwegian nursing homes and home care patients; control and prevention. J Hosp Infect 2000:45: 160-4.

19 Alberici F, Pagani L, Ratti G, et al. Ivermectin alone or in combination with benzyl benzoate in the treatment of human immunodeficiency virus associated scabies. Br J Dermatol 2000;142:969-72.

20 Konstantinov D, Stanoava I, Yawalker SJ. Crotamiton cream and lotion in the treatment of infants with scabies. J Int Med Res 1979:7:443.

21 Cubela V. Clinical experience with crotamiton cream and lotion in the treatment of infants with scabies. Br J Clin Pract 1978;32:229-31

22 Percival GH. The cure of scabies and a new remedy. BMJ 1942;ii:451-2.

23 Wooldridge WE. The gamma isomer of hexachlorcyclohexane in the treatment of scabies. J Invest Dermatol 1948;10:363-6.

24 Solomon LM, Fahrener L, West DP. Gamma benzene hexachloride toxicity: a review. Arch Dermatol 1977;113:353-7.

25 Ramussen JE. The problem of lindane. J Am Acad Dermatol 1981:5:507-16.

26 Rauch AE, Kowalsky SF, Leser TS, et al. Gamma benzene hexachloride (Kwell) induced aplastic anemia. Arch Intern Med 1990;150:2393-5.

27 Purvis RS, Tyring SK. An outbreak of lindane resistant scabies treated successfully with permethrin 5\% cream. J Am Acad Dermatol 1991;25:1015-16.

28 Paasch U, Haustein UF. Management of endemic outbreaks of scabies with allethrin, permethrin and ivermectin. Int J Dermatol 2000;39:463-70.

29 Meinking TL, Taplin D, Hermida JL, et al. The treatment of scabies with ivermectin. N Engl J Med 1995;333:26-30.

30 Aubin F, Humbert P. Ivermectin for crusted scabies. N Engl J Med 1995;332:612.

31 Dourmishev A, Serfimova D, Dourmishev L. Efficacy and tolerance of oral ivermectin in scabies. J Eur Acad Dermatol Venereol 1998;11:247-51.

32 Huffam SE, Currie BJ. Ivermectin for sarcoptes scabiei hyperinfestation. Int J Infect Dis 1998;2:152-4.

33 Youssef MYM, Sadaka HAH, Eissa MM, et al. Topical application of ivermectin for human ectoparasites. Am J Trop Med Hyg 1995:53:652-3.

34 Centers for Disease Control and Prevention. Sexually transmitted diseases treatment guidelines. 2002. MMWR Morb Mortal Wkly Rep 200;5(RR6):67-9.

35 Thappa DM, Karthikeyan K. Exaggerated scabies in a child. Indian Pediatr 2002;39:875-6.

36 Hernandez-Perez E. Resistance to antiscabietic drugs. J Am Acad Dermatol 1983;8:121-3.

37 Roth WI. Scabies resistant to lindane 1\% lotion and crotamiton 10\% cream. J Am Acad Dermatol 1991;24:502-3. 